\title{
THE ASSESSMENT OF FUNCTIONAL AND PSYCHO-EMOTIONAL STATUS IN COMPLEX MEDICAL REHABILITATION OF PATIENTS WITH RHEUMATOID DISEASES
}

\section{Victoria CHIHAI ${ }^{1 凶}$, Alisa TABIRTA ${ }^{1}$, Anatolie VIZDOAGA ${ }^{1}$, Lucia MAZUR-NICORICI ${ }^{2}$, Oleg PASCAL ${ }^{1}$, Minodora MAZUR ${ }^{3}$}

${ }^{1}$ Department of Medical Rehabilitation, Physical Medicine and Manual Therapy, "Nicolae Testemitanu" State University of Medicine and Pharmacy, Chisinau, Republic of Moldova

${ }^{2}$ Department of Internal Medicine, "Nicolae Testemitanu" State University of Medicine and Pharmacy, Chisinau, Republic of Moldova,

${ }^{3}$ Department of Internal Medicine, Discipline of Internal Medicine-Semiology, "Nicolae Testemitanu" State University of Medicine and Pharmacy, Chisinau, Republic of Moldova

Received 20 Oct 2020, Corrections received 23 Oct 2020, Accepted 29 Oct 2020

https://doi.org/10.31688/ABMU.2020.55.4.10

\section{Abstract}

Introduction. Rheumatoid arthritis (RA) is a systemic, chronic condition that belongs to autoimmune diseases, characterized by synovial membrane damage with the involvement of connective tissue, which leads to important functional limitations.

The objective of the study was to estimate the functional and psycho-emotional status in people with rheumatic damage in relation to the degree of activity and differentiated programs of medical rehabilitation. Material and methods. The data were collected from 67 patients diagnosed with moderate activity RA, aged $29-73$ years, of both sexes, randomized in 2 groups (test group $\mathrm{L}(\mathrm{T})$ - 31 patients, and control group $\mathrm{L}(\mathrm{C})-36$ patients). Patients in the test group were involved in medical rehabilitation programs with active-assisted kinetic techniques, individualized for each patient. All

\section{Résumé}

Lévaluation de l'état fonctionnel et psycho-émotionnel dans la réhabilitation médicale complexe des patients aux maladies rhumatoïdes

Introduction. La polyarthrite rhumatoïde (PR) est une maladie chronique systémique appartenant aux maladies auto-immunes, caractérisée par la présence de lésions de la membrane synoviale avec atteinte du tissu conjonctif, ce qui entraîne d'importantes limitations fonctionnelles.

Le but de l'étude était l'estimation de l'état fonctionnel et psycho-émotionnel chez les personnes souffrant de lésions rhumatismales en fonction du degré d'activité et des programmes différenciés de réadaptation médicale. 
persons included in the study were clinically-functionally examined with the application of a set of identical functional tests at admission and again, more than one month after treatment. The functional capacity of the hand was assessed by testing bi-digital, poly-digital and palm-based forceps (dots). The severity of the pain was assessed by visual analogue scale. The SF-11 (Medical Outcomes Study Short-Form Health Survey) scale was applied to assess the quality of life. The results obtained were analyzed using the Student test $(p<0.05$ value considered statistically significant).

Results. One month after initiation of physiotherapeutic rehabilitation treatment in the $\mathrm{L}(\mathrm{T})$ test group, the average pain value decreased from $78.531 \pm 1.36$ to $51.231 \pm 1.38(p<0.001)$ points. The testing of the hand function in the $L(T)$ test group showed an increase in scores from $4.27 \pm 1.25$ to $7.31 \pm 1.03(\mathrm{p}<0.01)$ points. Application of the SF11 scale one month after treatment revealed in the $L(T)$ test group the increase in psycho-emotional parameters: mental state (MS) from $40.12 \pm 2.13$ to $72.14 \pm 7.1$ ( $p<0.01)$ points; functioning of the emotional role (ER) from $27.24 \pm 1.23$ to $68.43 \pm 3.12$ $(\mathrm{p}<0.01)$ points, vitality (VT) from $22.37 \pm 4.32$ to $35.28 \pm 3.14(\mathrm{p}<0.01)$ points.

Conclusions. Medical rehabilitation programs with kinetic techniques have considerably improved clinical-functional manifestations, by reducing pain and improving hand function, mental state, emotional role, and general perception of health in people with rheumatic damage.

Keywords: quality of life, rheumatic damage to the hand, functional status.
Matériel et méthodes. Les données collectées auprès de 67 personnes diagnostiquées avec une PR à activité modérée, âgées de 29 à 73 ans des deux sexes ont été randomisées en 2 groupes (groupe test L (T) 31 personnes et groupe témoin L (C) - 36 personnes). Les patients du groupe test ont été impliqués dans des programmes de rééducation médicale avec des techniques cinétiques actives assistées, individualisées pour chaque patient. Toutes les personnes incluses dans l'étude ont été examinées cliniquement-fonctionnellement avec l'application d'un ensemble de tests fonctionnels identiques à l'admission (initiale) et à nouveau, plus d'un mois après le traitement. La capacité fonctionnelle de la main a été évaluée au moyen de pinces bi-digitales, poly-digitales et de la paume de la main (points). La sévérité de la douleur a été évaluée par une échelle visuelle analogue. L'échelle SF-11 (Medical Outcomes Study Short-Form Health Survey) a été appliquée pour évaluer la qualité de la vie. Les résultats obtenus ont été analysés à l'aide du test de Student (valeur $\mathrm{p}<0,05$ considérée comme statistiquement significative).

Résultats. Un mois après le début du traitement de rééducation physio-thérapeutique dans le groupe test L (T), la valeur moyenne de la douleur a diminué de $78,531 \pm 1,36$ à $51,231 \pm 1,38(\mathrm{p}<0,001)$ points. Le test de la fonction de la main dans le groupe de test $\mathrm{L}(\mathrm{T})$ a montré une augmentation des scores de 4,27 $\pm 1,25$ à 7,31 $\pm 1,03(\mathrm{p}<0,01)$ points. L'application de l'échelle SF11 après un mois de traitement a révélé dans le groupe test $\mathrm{L}(\mathrm{T})$ l'augmentation des paramètres psycho-émotionnels: l'état mental (EM) de 40,12 $\pm 2,13$ à $72,14 \pm 7,1$ ( $<<0,01)$ points: le fonctionnement du rôle émotionnel (RE) de 27,24 $\pm 1,23$ à $68,43 \pm 3,12(\mathrm{p}<0,01)$ points, la vitalité (VT) de 22,37 $\pm 4,32$ à $35,28 \pm 3,14$ (p $<0,01)$ points.

Conclusions. Les programmes de réadaptation médicale par des techniques cinétiques ont considérablement amélioré les manifestations cliniques-fonctionnelles, en réduisant la douleur et en améliorant la fonction de la main, l'état mental, le rôle émotionnel et la perception générale de la santé chez les personnes atteintes de lésions rhumatismales.

Mots-clés: qualité de la vie, lésions rhumatismales de la main, état fonctionnel.

of RA in Chinese women aged 50-59 is $22.1 \%$, and in South African women of the same age is $29.2 \%$; while the prevalence of RA in Chinese and African men aged 50-59 is only 2.3\% $\%^{2}$. RA has an increased predilection for the female sex, the ratio women: men being 2.2-2.5:1, and in middle-aged patients (from 35 to 55 years) reaches $5: 1^{3}$. The onset of the 
disease can occur at any age. For people genetically predisposed to the disease, one of the factors that trigger RA can be the polluted environment, smoking, diet, obesity, infections and the microbiota ${ }^{4}$. It is estimated that in developed countries, 5 years after diagnosis, $40 \%$ of people with RA are no longer able to work full-time, and 10 years after diagnosis they manage to work only $50 \%$ of the working norm ${ }^{5}$. The severity of the disease results from the fact that more than $50 \%$ of patients cease their professional activity during the first 5 years of the disease, and in $10 \%$ of cases a serious disability occurs in the first 2 years ${ }^{6,7}$. In the Republic of Moldova, the prevalence of osteo-articular diseases, including RA in adults, is 39.1 per 1000 inhabitants, with incidence rates of 14 cases per year, where each third patient is a female ${ }^{8}$. Thus, RA affects people at productive age, who with the advancement of the inflammatory and destructive process develop an inability to carry out their professional activities and have an advanced level of disability ${ }^{9}$. The severity of the inflammatory process in the joints of the hand causes to $50 \%$ of people to limit their professional activity in the first 5 years of the disease, and $10 \%$ of them will develop a disability even in the first 2 years from the onset ${ }^{10}$. According to the literature data ${ }^{11}$, in time, there is an increase in musculoskeletal and functional deficit, which limits the activities and functional independence of these persons, which in turn cause mental and emotional disorders. Progressive joint disorders are the cause of both significant functional disability and impotence, as well as depressive and anxious disorders in patients with RA, compared to the general population ${ }^{12}$. The results of some research demonstrate that psychological assistance and social support have a considerable impact on the quality of life of patients with $\mathrm{RA}^{13}$. The balanced psycho-emotional status of the patient increases the effectiveness of the drug and physio-functional treatment ${ }^{14}$. Currently, new approaches were selected in the complex treatment of these individuals, the aim of which is to improve functional capacities and quality of life by reducing the social impact of the disease and direct and indirect costs ${ }^{15,16}$. Taking into account the young age of people with RA (functional limitations and unbalanced psycho-emotional status that influence the degree of social involvement), a study in the rehabilitation of these deficiencies in relation to the degrees of activity of the disease is welcome $e^{17,18}$.

The obJective OF THE STUdY was to estimate the functional and psycho-emotional status in people with rheumatic damage of the hand joints, in relation to the degree of activity and deferential programs of medical rehabilitation.

\section{Material AND MEthods}

The study was conducted between November 2016 and December 2019 on a sample of 67 people diagnosed with RA, rated with the degree of activity and average duration of the disease, aged between $29-73$ years. Patients received functional rehabilitation treatment (kinetic therapy, electrotherapy and thermotherapy) for 10 days in the University Centre for Medical Rehabilitation of the State University of Medicine and Pharmacy "Nicolae Testemitanu", Chisinau, Republic of Moldova, and then they continued physiotherapy at home.

The activity of the disease was assessed as moderate activity, the activity degree DAS 28 with variation intervals 2.4-3.7 points. The participation in the study was informed (approval of the Research Ethics Commission No 1/21.01.2016). All the patients signed an informed consent. Criteria for inclusion: age 18-75 years, signed consent of the patient. Patients in the research group were randomized into test group $\mathrm{L}(\mathrm{T})$ - 31 persons, and control group L(C) 36 persons.

Patients in both groups received conventional rehabilitation treatment: locally applied electrotherapy, physical therapy, local thermotherapy. The test group was involved in medical rehabilitation programs with active assisted kinetic techniques, individualized for each patient in 2 sessions per day for 30 minutes. Individual programs were designed to increase the functional mobility of the hand and directed to amplify finger movements and eye/hand coordination, restore handling capacity for different objects, re-adapt to the functional hand deficit. All persons included in the study were clinically and functionally examined with the application of a set of identical functional tests at inclusion and after more than one month of functional treatment, with quality of life assessment. Functional hand capabilities were assessed by: bi-digital forceps testing (dots), poly-digital forceps testing (dots), and palm forceps testing (dots). The effectiveness of programs in combating with the intensity of pain has been quantified using the visual analogue scale of pain (VAS). The severity of pain was assessed by the visual analogue scale of 100 points, which allows subjective evaluation of pain, where the value " $O$ " corresponds to the $a b$ sence of pain, and the value " 100 " to maximum pain. Psycho-emotional status was assessed by the quality of life, with application of the SF-11 (Medical Outcomes Study Short-Form Health Survey) scale. This tool has been selected because it is practical, well-adapted to clinical use, inexpensive and has been validated for several chronic diseases in adults. Through 11 simple questions that are scored from 1 to 6, SF-11 
allows reproducible measurement of patient well-being on the following dimensions: physical strength function $(\mathrm{PhF})$, physical role $(\mathrm{PhR})$, general physical state (GPhS) social functioning (SF), functioning of emotional role (ER), vitality (VT), general pain (GP), mental state (MS), general perceptions of health (GP). Scores range from 0 to 100; the higher the score, the better the quality of life. The questionnaire included a brief introduction, which clearly explained the purpose of the study. The results were analyzed using the Student test ( $p<0.05$ value considered statistically significant).

The statistical analysis of the obtained data was performed in Excel and MedCalc v.1.2, by calculating arithmetic mean and standard deviation.

\section{Results}

In accordance with the established tasks, the study group included 67 patients with RA who met the inclusion criteria. We analyzed the demographic parameters in patients examined; the results obtained are shown in Table 1.

The results reveal the predominance of women $(56.72 \%)$ in the study group, with a female/male ratio of $1.31 / 1$. After the segregation of subjects in the study group by place of residence, we highlighted their preponderance in urban space. We analyzed the marital status of patients with rheumatoid arthritis and found that at the time of research 56 (83.58\%) were married and lived with families, $4.47 \%$ and
$2.98 \%$ of cases were divorced or solitary, and $8.95 \%$ of the subjects included in the study were widowed. We considered people who lived with the patients studied at the time of the examination and found that $71.64 \%$ and $20.89 \%$ of them lived with their spouse, partner or children, and $7.46 \%$ lived alone.

We continued the research by estimating the main clinical manifestations of rheumatoid arthritis in women and in men (Table 2). Table 2 shows that morning rigidity was more common in women versus men, $68.42 \%$ and $62.07 \%$, respectively. We noticed that the morning rigidity lasted from 20 to $120 \mathrm{~min}$ utes, the average being $73.3 \pm 0.5$ minutes. Other diagnostic criteria were symmetric arthritis, which was present in $54(80.59 \%)$ patients, this being simultaneous bilaterally in the interphalangeal, metacarpophalangeal, radiocarpal and knee joints. Symmetric arthritis was mentioned more frequently by women in $33(86.84 \%)$ cases compared to $21(72.42 \%)$ cases between men. We analyzed cases of arthritis in 3 and more joints, examining each joint, and found its presence in $97.37 \%$ of cases in women and $93.12 \%$ in men.

According to the objectives set, we used the Visual Analogue Scale (VAS) to assess and quantify pain experienced by subjects. The values of the initial pain and one month after treatment are shown in Figure 1. The analysis of data in Figure 1 shows that one month after the initiation of assisted physiotherapeutic rehabilitation treatment in the test group $(\mathrm{L}(\mathrm{T})$, the average pain value decreased from

Table 1. Demographic data of patients in the study group.

\begin{tabular}{llcc}
\hline & \multicolumn{1}{c}{ Variable } & Patients, No & (\%) \\
\hline \multirow{2}{*}{ Gender: } & Women & 38 & 56.72 \\
& Men & 29 & 43.28 \\
\hline \multirow{2}{*}{ Place of residence: } & Rural & 32 & 47.76 \\
& Urban & 35 & 52.24 \\
\hline \multirow{2}{*}{ Marital status: } & Married & 56 & 83.58 \\
& Divorced & 3 & 4.47 \\
& Bachelor & 2 & 2.98 \\
& Widower & 6 & 8.95 \\
\hline \multirow{2}{*}{ Living with: } & Spouse / Partner & 48 & 71.64 \\
& Children & 14 & 20.89 \\
& Single & 5 & 7.46 \\
\hline
\end{tabular}

Table 2. Distribution in the study group of the main clinical manifestations of RA.

\begin{tabular}{|c|c|c|c|c|c|c|c|c|c|c|c|c|}
\hline \multirow{3}{*}{ Gender } & \multicolumn{4}{|c|}{ Morning rigidity } & \multicolumn{4}{|c|}{ Symmetric arthritis } & \multicolumn{4}{|c|}{ Arthritis in $>3$ joints } \\
\hline & \multicolumn{2}{|c|}{ Absent } & \multicolumn{2}{|c|}{ Present } & \multicolumn{2}{|c|}{ Absent } & \multicolumn{2}{|c|}{ Present } & \multicolumn{2}{|c|}{ Absent } & \multicolumn{2}{|c|}{ Present } \\
\hline & $\mathrm{N}$ & $\%$ & $\mathrm{~N}$ & $\%$ & $\mathrm{~N}$ & $\%$ & $\mathrm{~N}$ & $\%$ & $\mathrm{~N}$ & $\%$ & $\mathrm{~N}$ & $\%$ \\
\hline Men & 11 & 37.93 & 18 & 62.07 & 8 & 27.58 & 21 & 72.42 & 2 & 6.88 & 27 & 93.12 \\
\hline Women & 12 & 31.58 & 26 & 68.42 & 5 & 13.16 & 33 & 86.84 & 1 & 2.63 & 37 & 97.37 \\
\hline Total & 23 & 34.33 & 44 & 65.67 & 13 & 19.41 & 54 & 80.59 & 3 & 4.48 & 64 & 95.52 \\
\hline
\end{tabular}


$78.531 \pm 1.36$ points to $51.231 \pm 1.38(\mathrm{p}<0.001)$ points after the visual analogue scale of pain. In the control group $(\mathrm{L}(\mathrm{C})$, the mean pain value decreased from $77.925 \pm 1.47$ to $62.576 \pm 1.13$ (p<0.001) (Fig. 1).

We continued the research with the assessment of the functional capabilities of the hand, by testing the bi-digital, poly-digital and palm forceps (Fig. 2).

Testing of the hand function in subjects who benefited from the combined treatment with assisted physical therapy $(\mathrm{L}(\mathrm{T})$ demonstrated an increase in scores for bi-digital $2.27 \pm 1.07$ to $3.7 \pm 1.03(\mathrm{p}<0.001)$ and for palm forceps from $3.24 \pm 1.09$ to $5.47 \pm 1.13$ $(\mathrm{p}<0.001)$. People who received conventional treatment $(\mathrm{L}(\mathrm{C})$ had a more modest increase in values for bi-digital forceps from $4.3 \pm 1.13$ to $6.81 \pm 1.04(\mathrm{p}<0.001)$ for poly-digital $2.31 \pm 1.08$ to $3.1 \pm 1.06(\mathrm{p}<0.001)$ and for palm forceps from $3.4 \pm 1.03$ to $5.17 \pm 1.03(\mathrm{p}<0.001)$ (Fig. 2).

Consequently, we were interested in assessing the quality of life in patients participating in the study, for the assessment of the general physical condition, emotional status, vitality and mental status in relation to the physio-functional treatment applied (Fig. 3, Fig. 4). Quality of life, evaluated with Scale SF 11, after one month of assisted kinetic treatment, had an increase in the final score for persons with moderate disease activity $(\mathrm{L}(\mathrm{T})$ in the dimensions of psycho-emotional parameters: mental state (MS) from $40.12 \pm 2.13$ to $72.14 \pm 7.15$ points, functioning of the emotional role (ER) from $27.24 \pm 1.23$ to $68.43 \pm 3.12$ points, vitality (VT) from $25.34 \pm 3.17$ to $45.27 \pm 2.16$ points, general health perceptions (HP) from

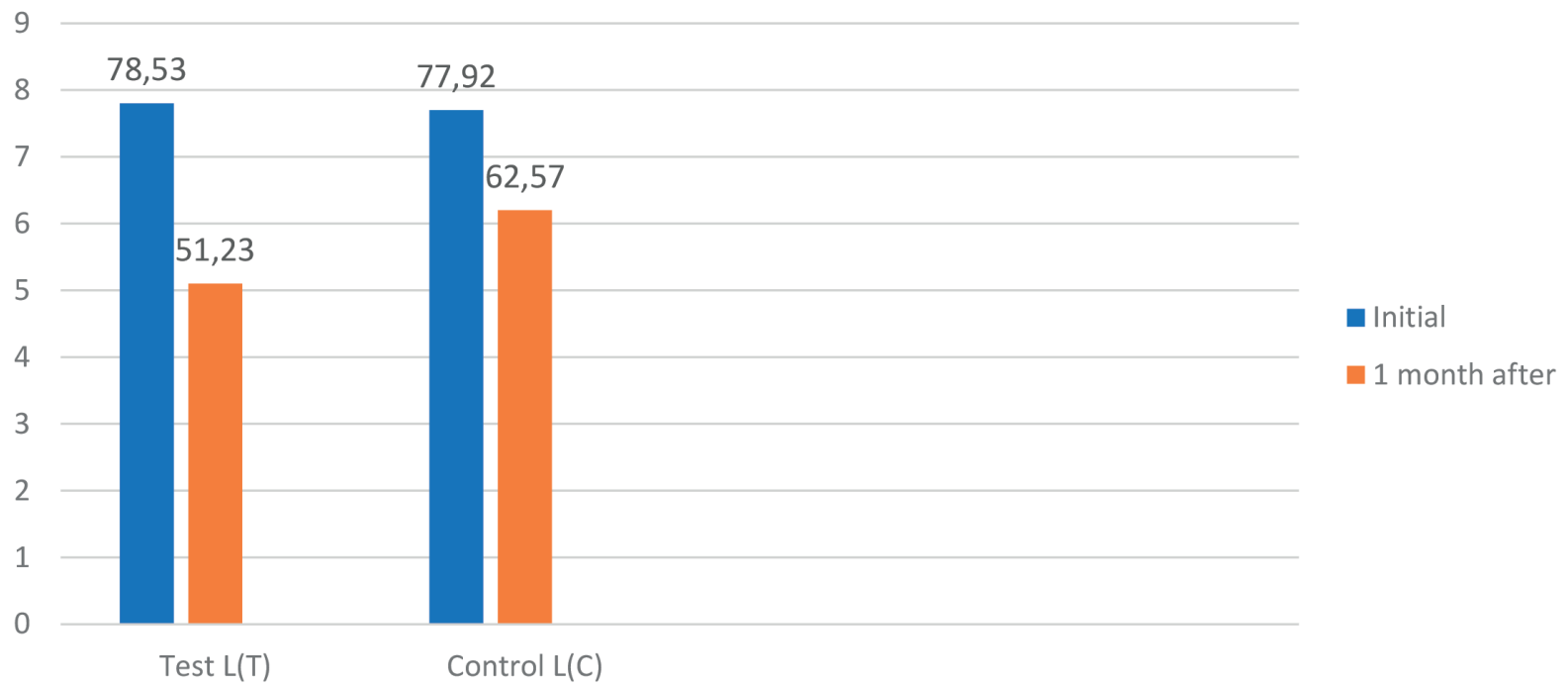

Figure 1. Average amount of pain in study groups

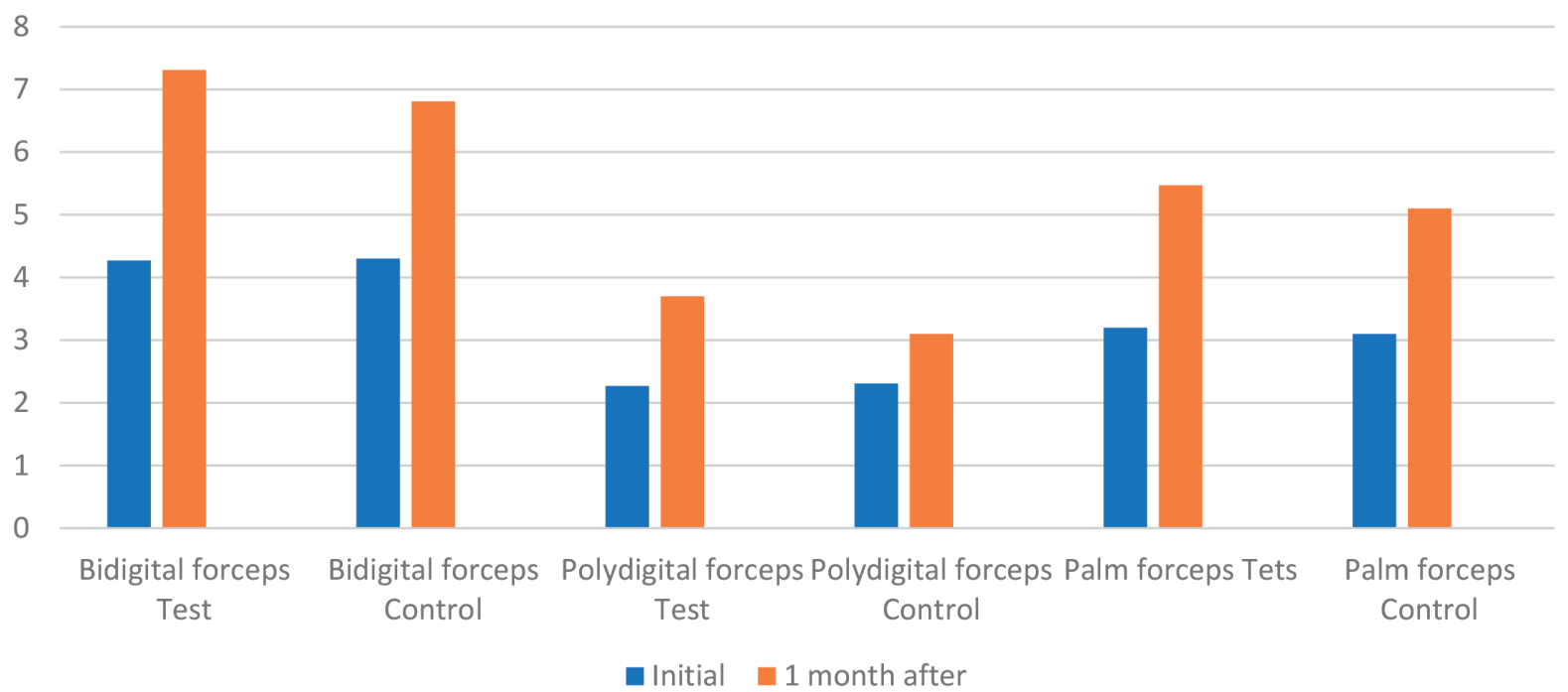

Figure 2. Testing of the hand function. 


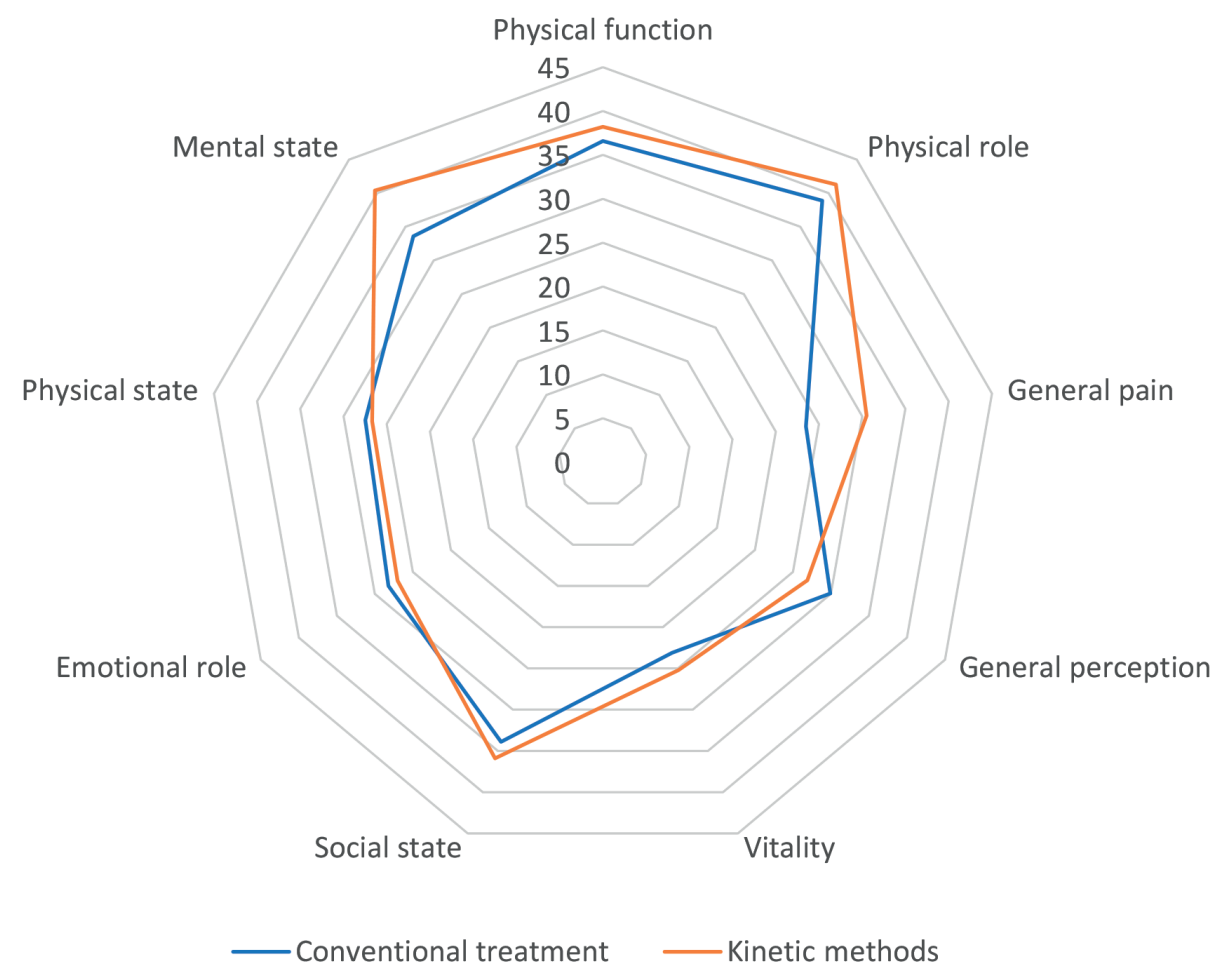

Figure 3. Initial value of quality of life indices in patients in both groups.

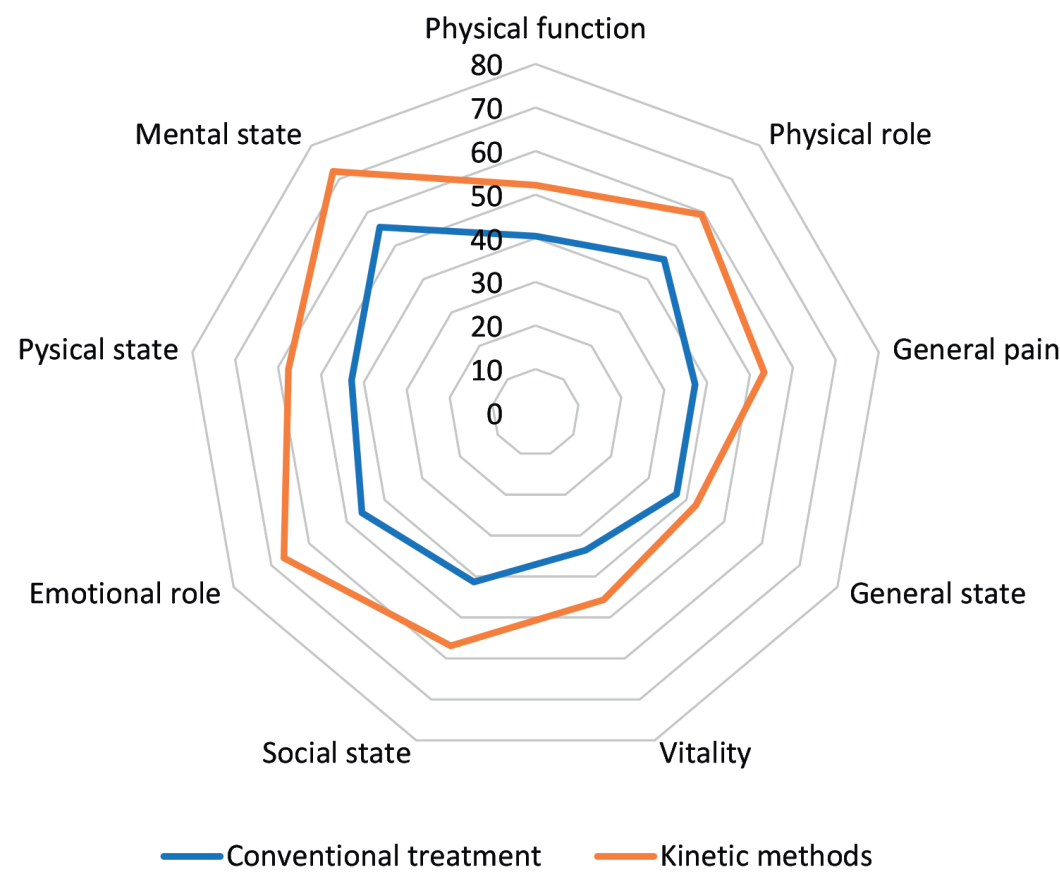

Figure 4. Value of quality of life indices after one month in both groups.

$36.42 \pm 4.18$ to $58.54 \pm 2.14$ points, social functioning (SF) from $22.13 \pm 3.17$ to $60.27 \pm 6.12$ points and parameters of physical activity: physical function $(\mathrm{PhF})$ from $39.26 \pm 2.17$ to $50.24 \pm 4.18$ points, physical role $(\mathrm{PhR})$ from $41.28 \pm 4.32$ to $60.15 \pm 3.17$ points, general physical state (GPhS) from $25.14 \pm 4.12$ to $60.32 \pm 2.18$ points. In the control group $\mathrm{L}(\mathrm{C})$, the increase in psycho-emotional parameters was lower: mental state (MS) from $35.12 \pm 4.12$ to $48.23 \pm 2.13$ points, functioning of emotional role (ER) from $29.53 \pm 2.18$ to 
$48.16 \pm 3.17$ points, vitality (VT) from $22.37 \pm 4.32$ to $35.28 \pm 3.14$ points, general health perceptions (GP) from $34.18 \pm 3.16$ to $41.32 \pm 7.19$ points, social functioning (SF) from $23.26 \pm 4.12$ to $45.21 \pm 3.17$ points and parameters of physical activity: physical function $(\mathrm{PhF}$ ) from $37.21 \pm 2.19$ to $40.34 \pm 6.13$ points, physical role $(\mathrm{PhR})$ from $35.17 \pm 2.18$ to $48.16 \pm 4.13$ points, general physical state (GPhS) from $24.23 \pm 4.27$ to 44.36 \pm 4.32 points (Fig. 3, Fig. 4).

\section{Discussion}

RA affects the joint structures, as well as joint synovial and extra-joint structures, generating hypertrophic synovitis, articular pain, with cartilage lesions and then the appearance of erosions of joint bone, with geodes and articular deformities. Thus, RA is the most complex form of chronic inflammatory pathology with systemic impairment. Symptomatic treatment applied from the onset of the disease rarely avoids the most serious and multiple joint deformities, serious dysfunctions, which leads to a high potential for disability or even severe disability ${ }^{19,20}$.

The National Council for Determining Disability and Work Capacity in the Republic of Moldova found the rate of disability in adult cases to be $87.54 \%$ in $2019^{21}$. The analysis of disabilities by age groups highlights the predominance of people with disabilities after the age of 50 years; the most affected being the age of 50-61 years (55\%). At the same time, the number of people with disabilities remains high for the age segment $40-49$ years (22\%). Disability in adults increased by $7.5 \%$ compared to 2018 (Report on the results of the activity of the National Council for Determining Disability and Work Capacity for 2019) ${ }^{21}$.

Depending on the nosology, diseases of the osteo-articular system, muscles and connective tissue form $12 \%$ (of which $43 \%$ are arthritis). One of the objectives of physio-functional rehabilitation of patients with osteo-articular disabilities is pain control ${ }^{22,23}$. In the present study, we evaluated pain parameters for patients with RA. In the study groups, the reduction of pain values by $34.7 \%$ in the test group $(\mathrm{L}(\mathrm{T})$ and $20.2 \%$ in the control group (L(C) is evident. Pain control was more effective in subjects' groups with conventional treatment combined with assisted kinetic methods. Maintaining increased mobility, joint stability and muscle tone of the hand were assessed by digital and palming functions. The participants of the test groups scored a more productive increase of joint mobility by $55 \%$ in $\mathrm{L}(\mathrm{T})$ compared to the control group participants by $42.9 \%$ in $\mathrm{L}(\mathrm{C})$. Educating the patient on the evolution of the disease $\mathrm{e}^{24}$ and the management of disabilities requires a stable psycho-emotional status, dependent on their physical status. In our study, we evaluated the quality of life based on psycho-emotional parameters and parameters of physical activity for patients with moderate activity of disease. After one month of physio-functional rehabilitation treatment in both study groups, a coherent increase in psycho-emotional and physical parameters was attested. In the test group, there was an increase in the physical function and physical role by $11 \%$ and $19 \%$, respectively. In the control group, the parameters of the physical function improved by only $13 \%$. The improvement in physical condition and physical function in the $\mathrm{L}(\mathrm{T})$ test group maintained a 32\% mental state and emotional role potential. In the control groups, the results were more modest: the emotional role amplified by $19 \%$ and the mental state by $13 \%$.

\section{Conclusions}

Medical rehabilitation programs with kinetic techniques have considerably improved clinical-functional manifestations, by reducing pain and improving hand function, in people with rheumatic damage of the joints of the hand, regardless of the degree of activity of the disease.

Positive dynamics in improving the integrative physical capacities of the hand showed a proportional correlation with the rise of psycho-emotional potential at the end of medical rehabilitation programs with active kinetic techniques.

The psycho-emotional status of patients with rheumatic damage of the hand joints, involved in medical rehabilitation programs with active kinetic techniques, had a considerable impact in improving the quality of life, according to the SF-11 scale.

\section{Author Contributions:}

Conceptualization, M.M. and V.C.; methodology, V.C.; software, A.T.; validation ,A.T., L.M.-N. and V.C.; formal analysis, O.P.; investigation, A.V.; resources, data V.C.; curation, M.M and O.P.; writing-original draft preparation, V.C.; writing-review and editing, V.C., M.M, A.T.,L.M.-N.; visualization, O.P. and M.M.; supervision, M.M; project administration, O.P. All the authors have read and agreed with the final version of the article.

\section{Compliance with Ethics Requirements:}

„The authors declare no conflict of interest regarding this article"

"The authors declare that all the procedures and experiments of this study respect the ethical standards in the Helsinki Declaration of 1975, as revised in 2008(5), as 
well as the national law. Informed consent was obtained from all the patients included in the study"

"No funding for this study"

\section{Acknowledgements:}

\section{None}

\section{References}

1. Conigliaro P, Triggianese P, De Martino E, et al. Challenges in the treatment of rheumatoid arthritis. Autoimmunity Reviews. 2019; 18 (7):706-713.

2. Brennan-Olsen SL, Cook S, Leech MT, et al. Prevalence of arthritis according to age, sex and socioeconomic status in six low- and middle-income countries: analysis of data from the World Health Organization study on global AGEing and adult health (SAGE) Wave 1. BMC Musculoskeletal Disorders. 2017; 18: 271.

3. Dorado J. A computer-vision-based system for at-home rheumatoid arthritis rehabilitation. International Journal of Distributed Sensor Network. 2019; 15 (9):1-15.

4. Croia C, Bursi R, Sutera D, et al. One year in review 2019: pathogenesis of rheumatoid arthritis. Clinical and Experimental Rheumatology. 2019; 37:347-357.

5. Okada Y, Eyre S, Suzuki A, et al. Genetics of rheumatoid arthritis: 2018 status. MBJ Journal Annals of Rheumatic Diseases. 2018; 78 (4):446-453.

6. Raza K, Holers VM, Gerlag D. Nomenclature for the phases of the development of rheumatoid arthritis. Clinical Therapeutics. 2019;41(7):1279-1285.

7. Chaplin S. Summary of the new EULAR rheumatoid arthritis guideline. Prescriber. 2020;31(9): 15-19.

8. Anuarul statistic al Republicii Moldova 2019:175-178.

9. Ambrosino P, Iannuzzi GL, Formisano R, et al. Exergaming as an additional tool in rehabilitation of young patients with rheumatoid arthritis: a pilot randomized controlled trial. Games for Health Journal. 2020; 9(5): 368-375.

10. Gatt A, Mercieca C, Borg A, et al. A comparison of thermographic characteristics of the hands and wrists of rheumatoid arthritis patients and healthy controls. Nature Research. Scientific Reports 2019; 9:221-235.

11. Nerurkar L, Siebert S, McInnes I, Cavanagh J. Rheumatoid arthritis and depression: an inflammatory perspective. The Lancet. 2019; 6(2):164-173.
12. Aoki T, Ito H, Ogura T, et al. Association of age with the non-achievement of clinical and functional remission in rheumatoid arthritis. Nature Research. Scientific Reports 2020; 10:152-177.

13. Strikesavan S, Bryer C, Ali U, Williamson E. Web-based rehabilitation interventions for people with rheumatoid arthritis: A systematic review. Journal of Telemedicine and Telecare. 2019; 25(5):263-275

14. Bernetti A. Spa therapy and rehabilitation of musculoskeletal pathologies: a proposal for best practice in Italy. International Journal of Biometeorology. 2019; 64: 905-914.

15. Kloppenburg M, Kroon F, Blanco FJ, et al. 2018 update of the EULAR recommendations for the management of hand osteoarthritis. BMJ Journals. Annals of Rheumatic Disease. 2018; 78 (1): 16-24.

16. Smolen JS, Landewe RMB, Bijlsma JWJ, et al. EULAR recommendations for the management of rheumatoid arthritis with synthetic and biological disease-modifying anti-rheumatic drugs: 2019 update. Annals of the Rheumatic Diseases. 2019; 79(6):685-699.

17. Hendry GJ, Bearne L, Foster N, et al. A mixed methods feasibility study of a gait rehabilitation programme for people with early rheumatoid arthritis and foot pain. Rheumatology. 2020;59(2):64

18. Lawson ND, Boyd WJ. Physician impairment and rehabilitation. Annals of Internal Medicine. 2019; 5:680-682.

19. Yoshioka H, Kadono Y, Kim YT, et al. Imaging evaluation of the cartilage in rheumatoid arthritis patients with an x-ray phase imaging apparatus based on Talbot-Lau interferometry. Scientific Reports. 2020; 10:1-9.

20. Rumrill P, Strauser D, Greco C, Mykal L. A vocational rehabilitation intervention framework for people with rheumatoid arthritis. Journal of Applied Rehabilitation Counseling. 2019; 51(1): 264-278.

21. Raport de totalizare a activității Consiliului Național pentru Determinarea Dizabilității și Capacității de Muncă în anul 2019 în Republica Moldova. 2019: 10-11.

22. Makkar R, Behl T, Bungau S, Kumar A, Arora S. Understanding the role of inflammasomes in rheumatoid arthritis. Inflammation. 2020; 43: 2033-2047.

23. Kaur I, Behl T, Bungau S, et al. Exploring the therapeutic promise of targeting HMGB1 in rheumatoid arthritis. Life Sciences. 2020; 258: 118164.

24. Behl T, Chadha S, Kumar A, Hafeez A, Mehta V, Bungau S. Ubiquitination in rheumatoid arthritis. Life Sciences. 2020; 261: 118459 . 